\title{
Silencing DNA methyltransferase 1 (DNMT1) inhibits proliferation, metastasis and invasion in ESCC by suppressing methylation of RASSF1A and DAPK
}

\author{
Jian Bai ${ }^{1}$, Xue Zhang ${ }^{2}$, Kai Hu ${ }^{3}$, Bangqing Liu ${ }^{1}$, Haiyong Wang ${ }^{3}$, Angui Li $^{3}$, Feng Lin ${ }^{3}$, \\ Lifei Zhang ${ }^{1}$, Xiaolin Sun ${ }^{3}$, Zhenzong Du ${ }^{1,4}$, Jianfei Song ${ }^{1,4}$ \\ ${ }^{1}$ Department of Thoracic \& Cardiovascular Surgery, The Second Affiliated Hospital of Guilin Medical University, Guilin, China \\ ${ }^{2}$ Department of ICU, The Second Affiliated Hospital of Guilin Medical University, Guilin, China \\ ${ }^{3}$ Department of Thoracic \& Cardiovascular Surgery, The Affiliated Hospital of Guilin Medical University, Guilin, China \\ ${ }^{4}$ Current address: Department of Thoracic \& Cardiovascular Surgery, The Second Affiliated Hospital of Guilin Medical \\ University, Lingui District, Guilin, China \\ Correspondence to: Jianfei Song, email: guilinsjf@163.com \\ Zhenzong Du, email: duzhenzong@sina.com \\ Keywords: ESCC, DNA methyltransferase 1, methylation, RASSF1A, DAPK \\ Received: July 27, 2015 \\ Accepted: March 31, 2016 \\ Published: June 07, 2016
}

\section{ABSTRACT}

Our previous study showed DNMT1 is up-regulated in esophageal squamous cell carcinoma (ESCC), which is associated with methylation of tumor suppressors. In the current study, we investigate the role of DNMT1 in ESCC. We found silencing DNMT1 inhibited proliferation, metastasis and invasion of three different ESCC cells, K150, K410 and K450. We also found silencing DNMT1 induced G1 arrest and cell apoptosis in K150, K410 and K450 cells. In vivo study showed silencing DNMT1 suppressed tumor growth in nude mice. In addition, silencing DNMT1 increased expression of tumor suppressor genes, RASSF1A and DAPK, in ESCC cells and ESCC xenograft in nude mice. Moreover, silencing DNMT1 decreased methylation in promoter of RASSF1A and DAPK. In conclusion, our data demonstrated that silencing DNMT1 inhibits proliferation, metastasis and invasion in ESCC by suppressing methylation of RASSF1A and DAPK.

\section{INTRODUCTION}

Esophageal squamous cell carcinoma (ESCC) is one of the most common malignancies in worldwide. The incidence of ESCC in China is much higher than other countries. Figuring out the molecular mechanisms of carcinogenesis, metastasis and invasion in ESCC will help improving efficiency of ESCC therapy. Although numerous efforts had been made, the mechanism of ESCC is not fully understood yet.

Recently, epigenetic silencing of tumor suppressor genes has been demonstrated as one of the most important mechanisms contributes to inactivation of tumor suppressor genes in cancer. Promoter methylation of tumor suppressor genes is a critical early step in carcinogenesis including that of ESCC. Our previous study indicates that the status of promoter methylation changes following the progression of ESCC. P16 methylation is a frequent and early event in ESCC. Methylation of MLH1 was associated with advanced stage ESCC. The aberrant methylation of tumor suppressor genes has also been used as a predictor of the clinical outcome following a curative resection of ESCC. Promoter methylation of APC and FHIT has been associated with reduced survival in ESCC patients after esophagectomy.

RASSF1A is member of Ras association (RalGDS/ AF-6) domain family [1]. Loss or altered expression of RASSF1A has been associated with the pathogenesis of a variety of cancers, which suggests the tumor suppressor function of this gene. The inactivation of RASSF1A was found to be correlated with the hypermethylation of its CpG-island promoter region [2-5]. Our previous study indicates methylation of RASSF1A associates with expression of DNMT1 [6] in ESCC. Death-associated protein kinase (DAPK) is an intracellular protein that mediates cell death by its serine/threonine kinase activity, and transmits apoptotic cell death signals [7, 8]. DAPK promoter methylation is associated with carcinogenesis [9].

DNA methyltransferase 1 (DNMT1) plays an important role in the establishment and regulation of tissue-specific patterns of methylated cytosine residues $[10,11]$. DNMT1 mediated epigenetic silencing of tumor 
suppressor genes contributes to the progression of cancer $[12,13]$, which makes DNMT1 the potential target of cancer therapy. Several studies report that RNAi mediated depletion of DNMT1 or microRNA mediated suppression of DNMT1 restores tumor suppressor genes expression through the reversal of DNA hypermethylation [14-17]. Our previous study show DNMT1 is highly expressed in ESCC specimens [6]. However, the function of DNMT1 in ESCC has not been reported.

In the present study, we investigate the effects of silencing DNMT1 on proliferation, metastasis and invasion of ESCC. The molecular mechanism underlying effects of silencing DNMT1 on ESCC is also examined by focusing on the methylation status of two tumor suppressor genes, RASSF1A and DAPK.

\section{RESULTS}

\section{Silencing DNMT1 inhibits proliferation, metastasis and invasion in ESCC cells}

Our previous study showed DNMT1 overexpressed in ESCC specimens. In order to investigate the role of DNMT1 in ESCC, we examined the effects of silencing DNMT1 on proliferation, metastasis and invasion in ESCC cells. We created three ESCC stable cell lines (K150-shRNA, K410-shRNA and K450-shRNA) which the expression of DNMT1 was suppressed by shRNA targeted DNMT1. Their corresponding control were ESCC cells infected with lentivirus-NC, which containing scramble sequence. To confirm the creation of ESCC stable cells, the mRNA and protein expression of DNMT1 were examined by quantitative real time RT-PCR and western blot, respectively. Our data showed both mRNA and protein expression of DNMT1 in three ESCC stable cell lines was significantly suppressed compare to their controls (Figure 1).

Cell proliferation assays and colony formation assays were performed to evaluate cell growth and colony formation ability of K150-shRNA, K410-shRNA and K450-shRNA stable cells. We found ESCC stable cells grew much slower and formed less colonies than their corresponding controls (Figure 2A and 2B). In vitro transwell assay was performed to evaluate metastasis and invasion abilities of ESCC stable cells. our data showed metastasis and invasion abilities of ESCC stable cells were much weaker than their corresponding controls (Figure 2C and 2D). These results indicates silencing DNMT1 inhibits proliferation, metastasis and invasion in ESCC cells.

\section{Silencing DNMT1 induces G1 arrest and apoptosis in ESCC cells}

In order to further explore the mechanism of inhibitory effects of silencing DNMT1 on ESCC, we performed cell cycle analysis and apoptosis analysis in ESCC stable cells. our data showed the percentage of G1 cells and apoptosis rate was increased in ESCC stable cells compared with their corresponding controls (Figure $3 \mathrm{~A}$ and $3 \mathrm{~B}$ ). These data suggest that silencing DNMT1 induces G1 arrest and apoptosis in ESCC cells.

\section{Silencing DNMT1 suppresses tumor growth in vivo}

We further verified these findings by examining the effects of silencing DNMT1 on tumor growth in nude mice. K150-shRNA, K410-shRNA and K450-shRNA

A
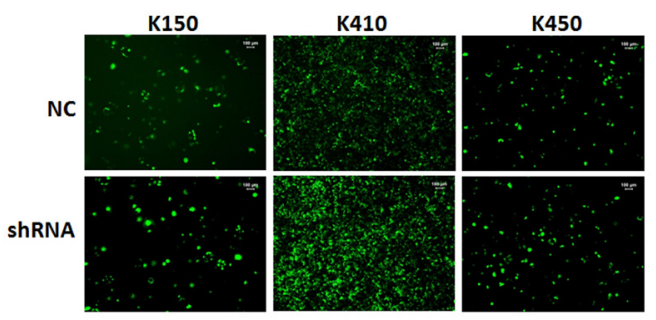

B
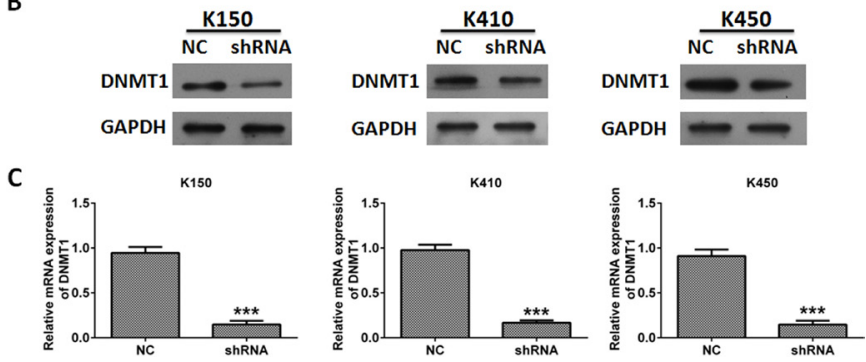

Figure 1: Silencing DNMT1 in ESCC cells. A. Representative pictures of ESCC cells infected with lentivirus. Magnification, 20 $\times$. B. The protein expression of DNMT1 in ESCC cells. GAPDH was served as loading control. C. The mRNA expression of DNMT1 in ESCC cells. mRNA expression of DNMT1 was normalized to GAPDH. Data represented as means \pm SD from three independent experiments. ${ }^{* * *}, p<0.001$. 
stable cells were injected subcutaneously into nude mice, respectively. Control groups were injected with K150-NC, K410-NC and K450-NC stable cells. The tumor sizes were recorded at day 7, 14, 21 and 28. We found group K140, group K410 and group K450 generated much smaller tumors than their corresponding controls (Figure 4A and 4B). Quantitative real time RT-PCR was performed to confirm the suppression of DNMT1 in tumors of nude mice (Figure 4C). These data suggest that silencing DNMT1 suppresses tumor growth in vivo.

\section{Silencing DNMT1 up-regulates expression of RASSF1A and DAPK}

In order to demonstrate the molecular mechanisms underlying inhibitory effects of silencing DNMT1 on ESCC cells, we investigated the effect of silencing DNMT1 on expression of tumor suppressor genes. Our data showed mRNA and protein expressions of RASSF1A and DAPK in K150-shRNA, K410-shRNA and K450shRNA stable cells were significantly higher than those in corresponding controls (Figure 5A and 5B). Similar results were obtained from tumors isolated from nude mice injected with ESCC stable cells (Figure 5C, 5D and 5E). These data suggest that silencing DNMT1 upregulates expression of RASSF1A and DAPK. This results were verified by rescue experiments by overexpression of RASSF1 and DAPK in DNMT1 knockdown cells (Supplementary Figure S3-S5).

\section{Silencing DNMT1 suppresses methylation of RASSF1A and DAPK}

Methylation of tumor suppressor genes, which results in down-regulation of tumor suppressor genes, is one of the mechanisms contribute to ESCC. To further demonstrate molecular mechanisms underlying effects of silencing DNMT1 on RASSF1A and DAPK, we analyzed methylation of RASSF1A and DAPK in ESCC stable cells by MSP and BSP. Our data showed methylation of RASSF1A and DAPK were inhibited in K150-shRNA, K410-shRNA and K450-shRNA stable cells, but not in their corresponding controls (Figure 6A \& Figure 7).

This finding was supported by results obtained from tumors isolated from nude mice injected with ESCC stable cells. Methylation of RASSF1A and DAPK were
A

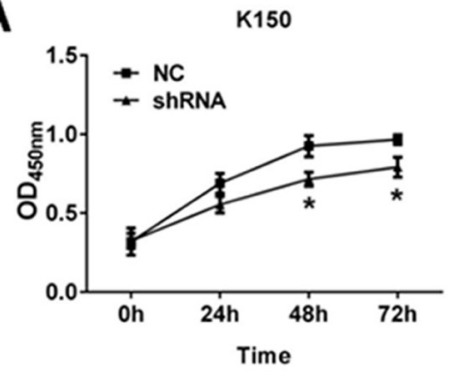

B
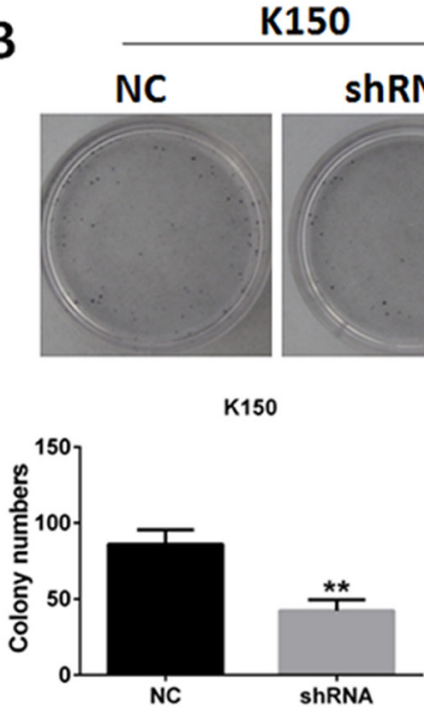

K410

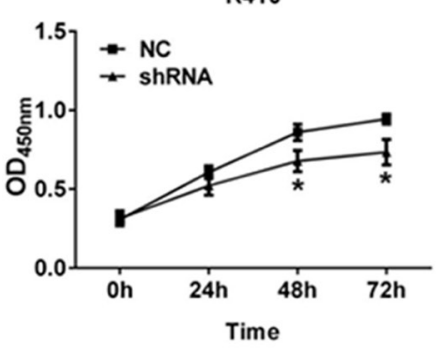

K410

NC

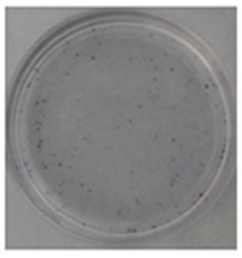

K410

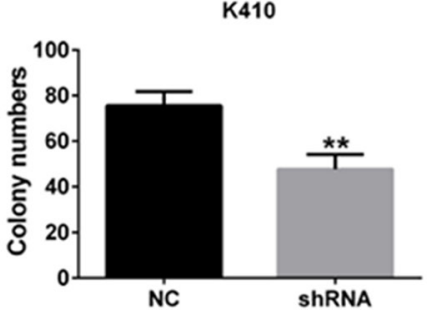

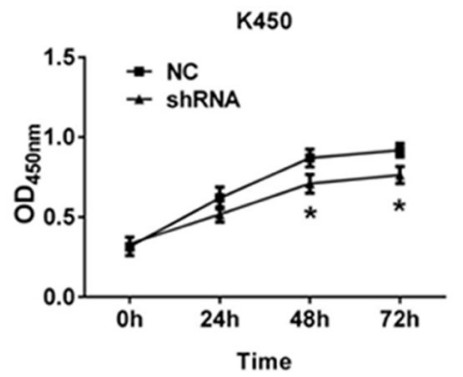

K450

NC

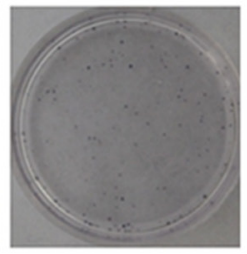

K410

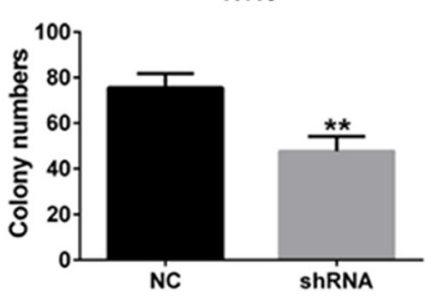

Figure 2: Silencing DNMT1 inhibited proliferation, metastasis and invasion in ESCC cells. A. MTT assays of ESCC cells. Data represented as means $\pm \mathrm{SD}$ from three independent experiments. ${ }^{*}, p<0.05$. B. colony formation assays of ESCC cells. Data represented as means $\pm \mathrm{SD}$ from three independent experiments. $* *, p<0.01$.

(Continued) 
C
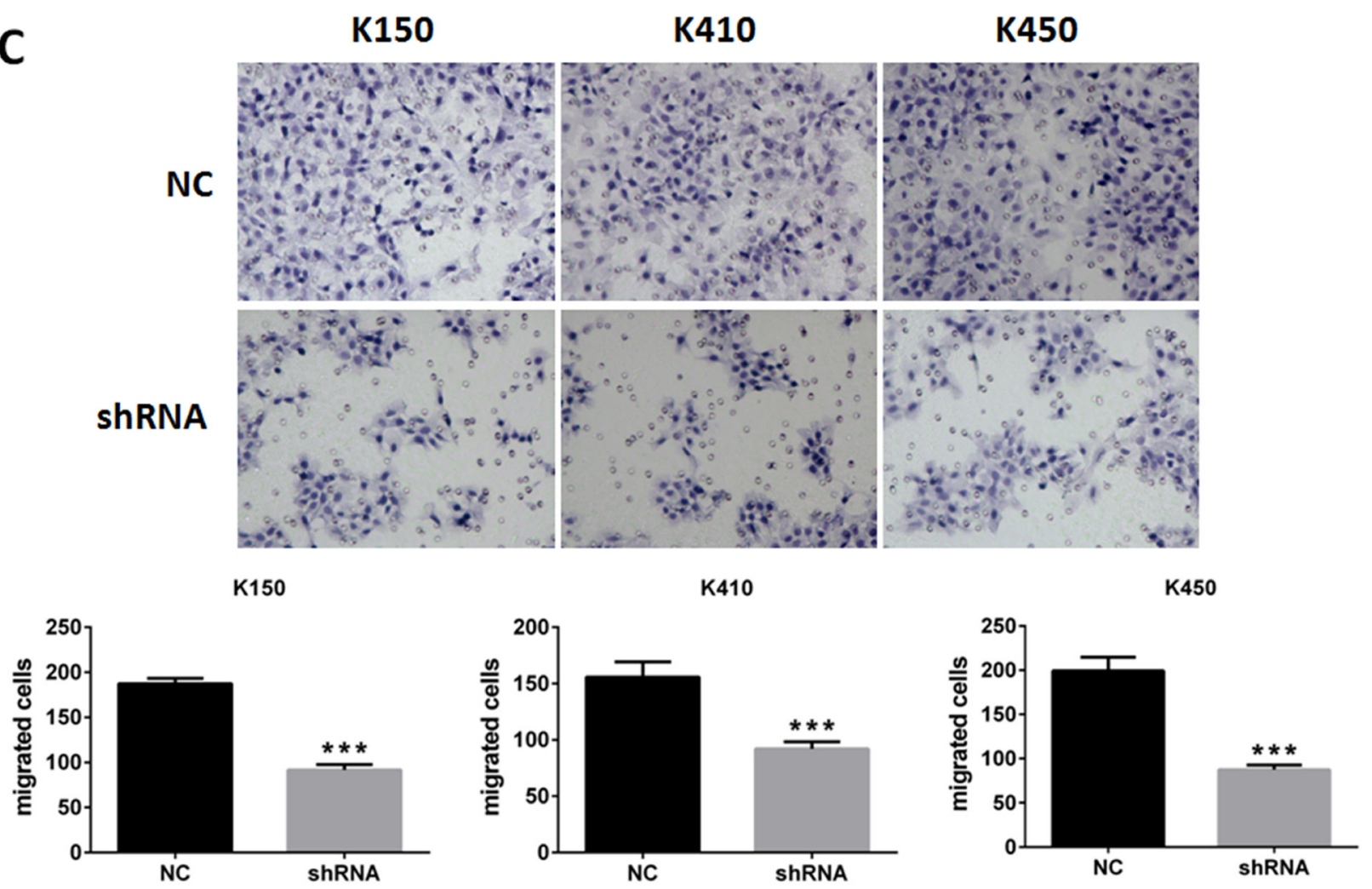

D
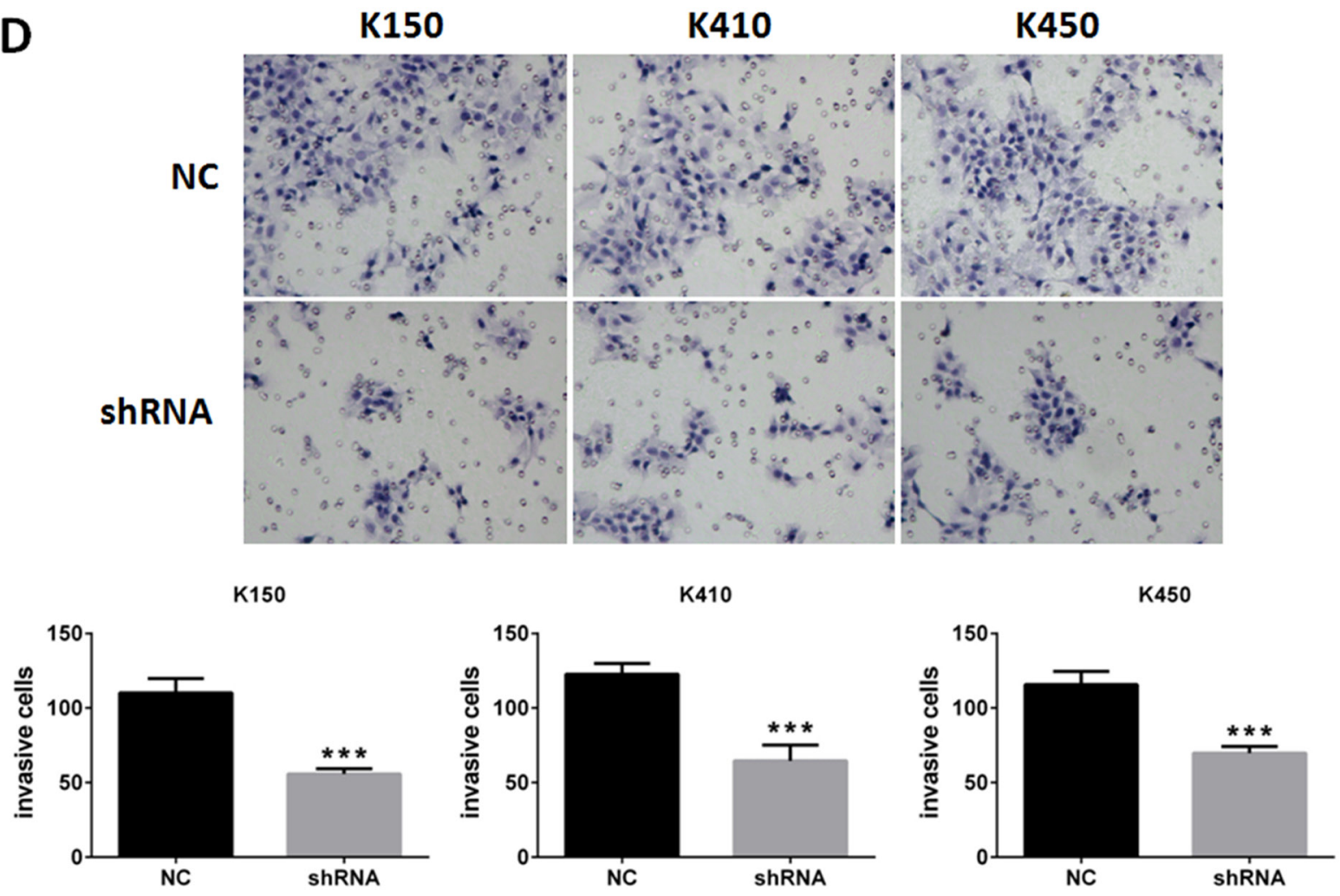

Figure 2 (Continued): C. metastasis assays of ESCC cells. original magnification, $20 \mathrm{X}$. Data represented as means \pm SD from three independent experiments. ${ }^{* *}, p<0.001$. D. invasion assays of ESCC cells. original magnification, $20 \times$. Data represented as means $\pm \mathrm{SD}$ from three independent experiments. ${ }^{* * *}, p<0.001$. 
A

NC
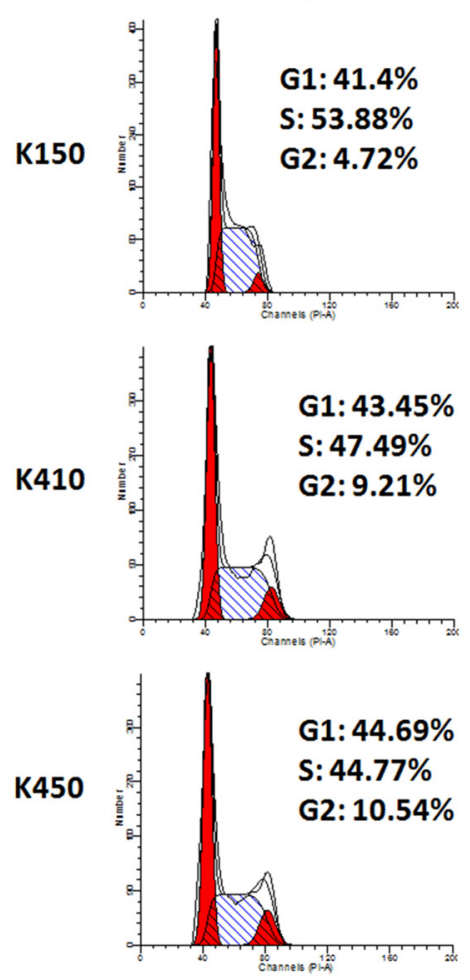

B
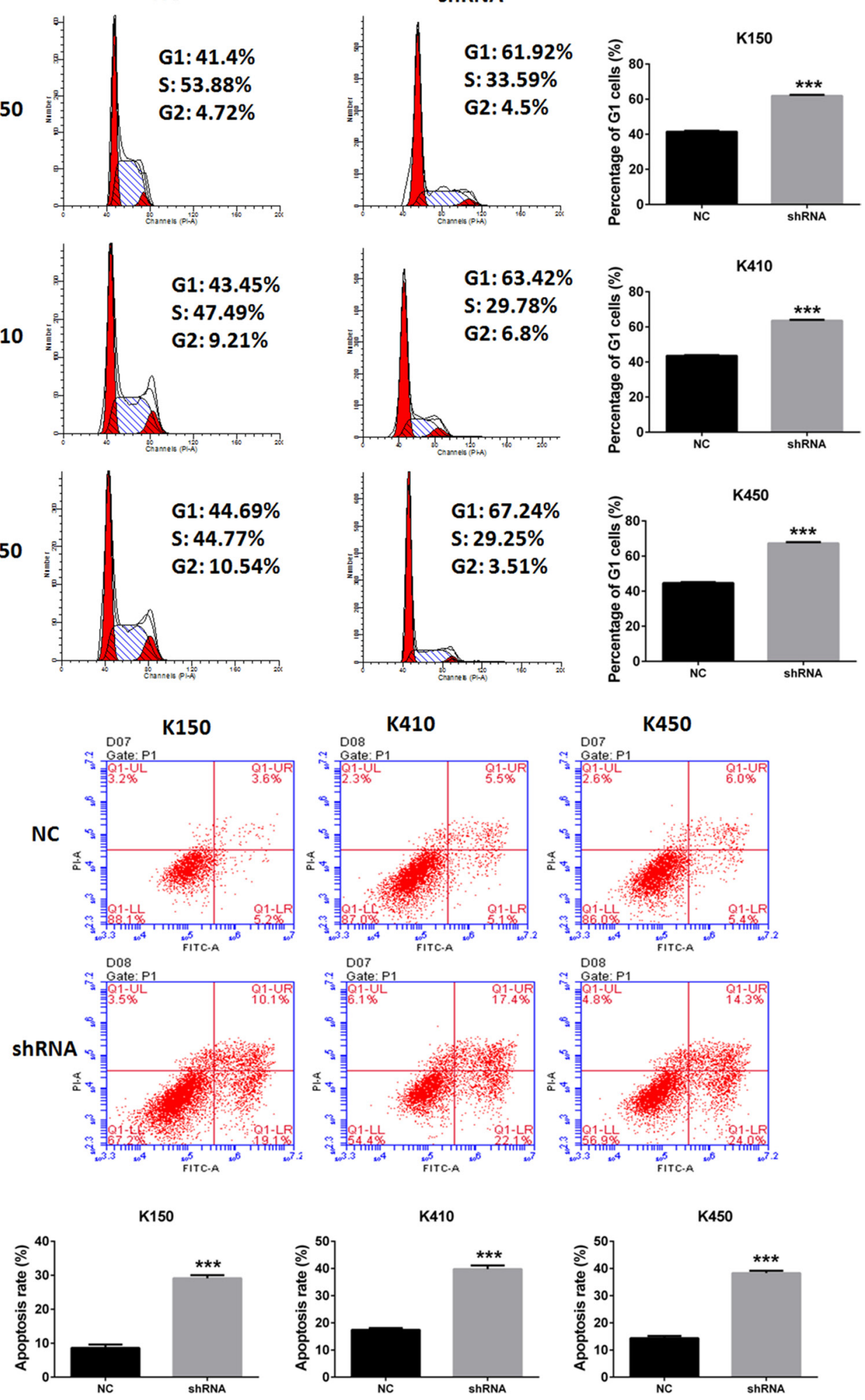

Figure 3: Silencing DNMT1 induced G1 arrest and apoptosis in ESCC cells. A. Cell cycle analysis of ESCC stable cells. Data represented as means $\pm \mathrm{SD}$ from three independent experiments. ${ }^{* * *}, p<0.001$. B. Apoptosis assays of ESCC stable cells. Data represented as means $\pm \mathrm{SD}$ from three independent experiments. ${ }^{* * *}, p<0.001$. 
both inhibited in tumors isolated from nude mice injected with ESCC stable cells compared with their corresponding controls (Figure 6B).

\section{DISCUSSION}

DNMT1 is required to maintained $\mathrm{CpG}$ methylation and aberrant gene silencing in multiple physical process and diseases, including cell differentiation [18, 19], $\mathrm{T}$ cell development and function [20], differentiation and function of stem cells [21-23], systemic lupus erythematosus [24], tumor initiation and progression [25-27]. Numerous studies demonstrate the crucial role of DNMT1 in various types of cancers, including acute myeloid leukemogenesis [28], breast cancer [29], prostate cancer [30], pancreatic cancer [30], lung cancer [31]. However, the role of DNMT1 in ESCC has not been investigated yet. In the current study, we report silencing DNMT1 inhibits proliferation, metastasis and invasion in ESCC cells, and suppresses tumor growth of ESCC in nude mice. Moreover, silencing DNMT1 induces G1 arrest and cell apoptosis in ESCC cells. Taken together, these data indicate silencing DNMT1 is a therapeutic target for ESCC therapy.

Previous studies demonstrates that DNMT1 mediated epigenetic silence of tumor related genes is the major mechanism contributes to carcinogenesis and progression of cancer. So, RNAi-mediated depletion of DNMT1, which results in $\mathrm{CpG}$ island demethylation and re-expression of tumor suppressor genes, may be a strategy for cancer therapy [32]. We have proved silencing DNMT is effective for inhibiting proliferation, colony formation, migration and invasion of ESCC cells. however, the molecular mechanism underlying inhibitory effects of silencing DNMT1 is not clear yet. In the current study, we focus on effects of silencing DNMT1 on expression and methylation status of DAPK, MGMT, RASSF1A, APC, ASC, P16 and CDH13, which has been reported

A
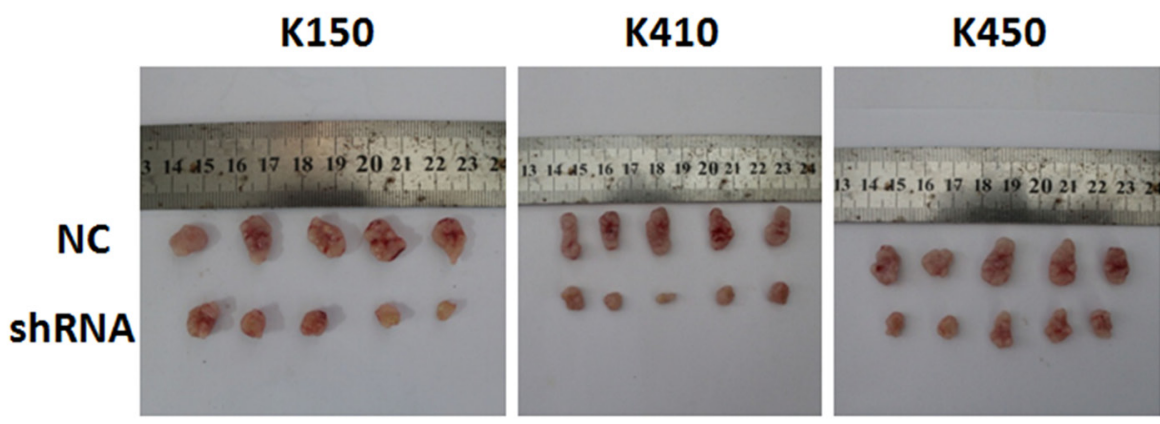

B
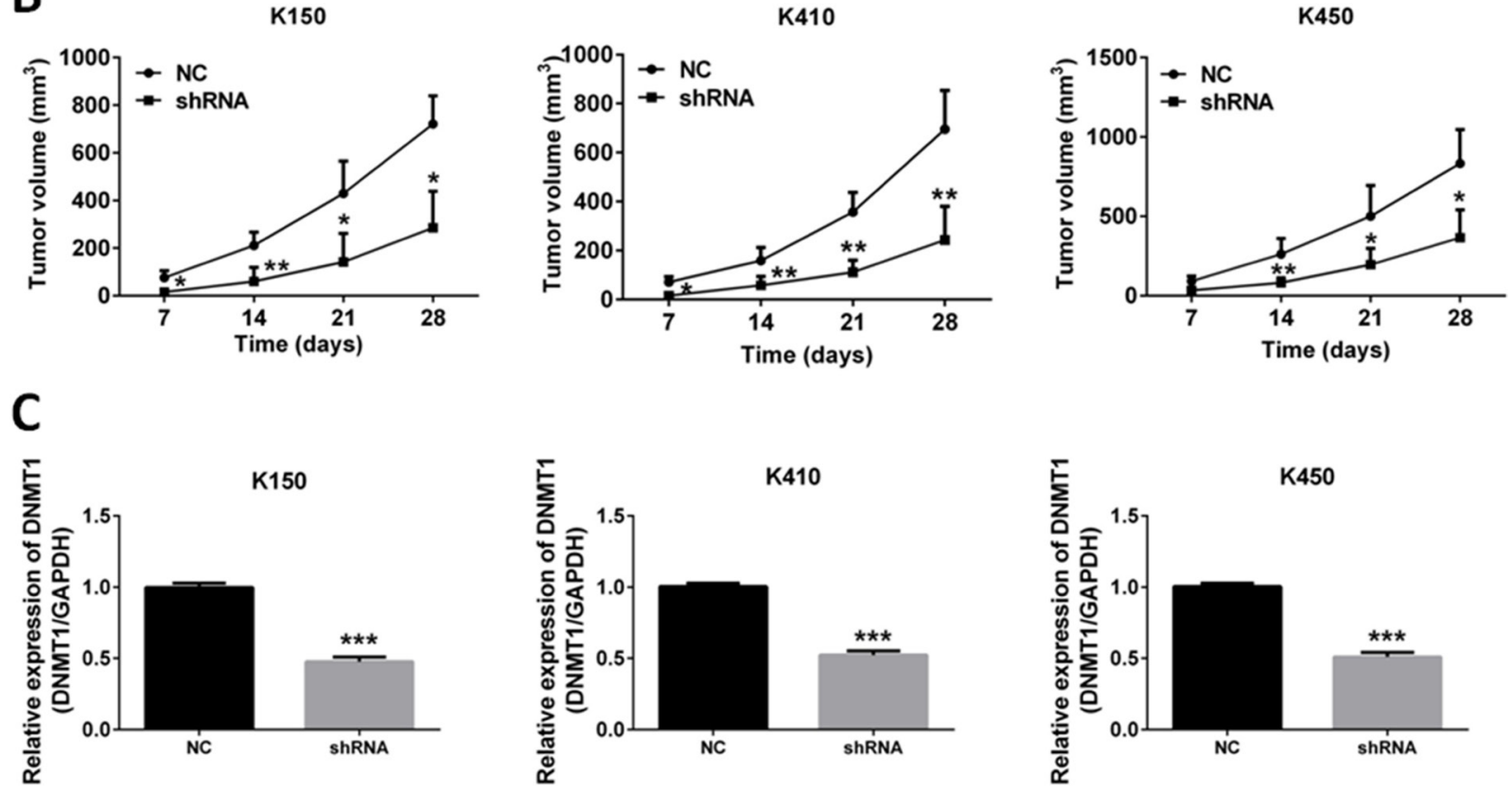

Figure 4: Silencing DNMT1 inhibited tumor growth in nude mice. A. Tumors isolated from nude mice injected with ESCC stable cells. B. Growth curve of Tumors. Data represented as means $\pm \mathrm{SD} .{ }^{*}, p<0.05 .{ }^{* *}, p<0.01$. C. expression of DNMT1 in tumors isolated from nude mice. Data represented as means $\pm \mathrm{SD}$. ***, $p<0.001$. 
A
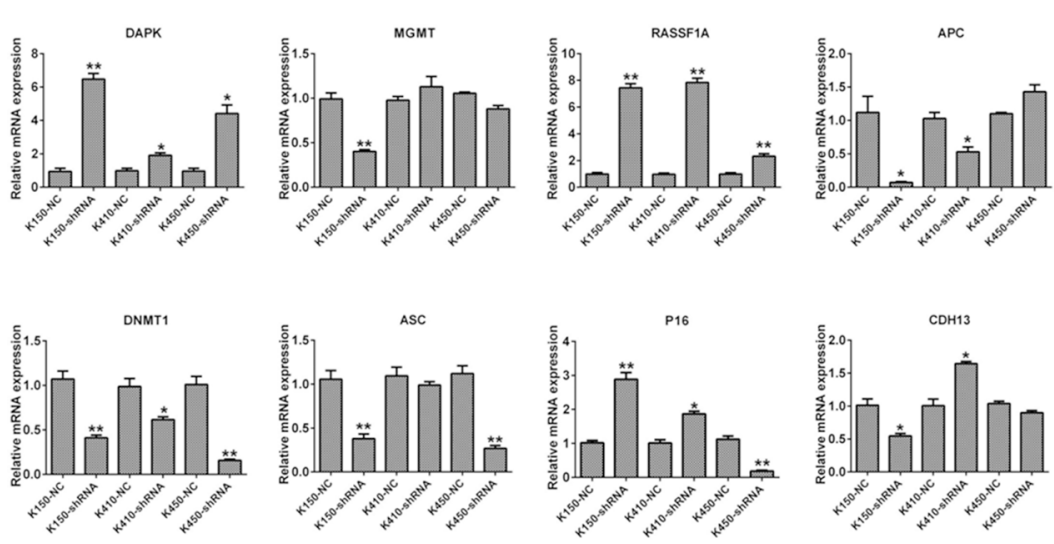

B
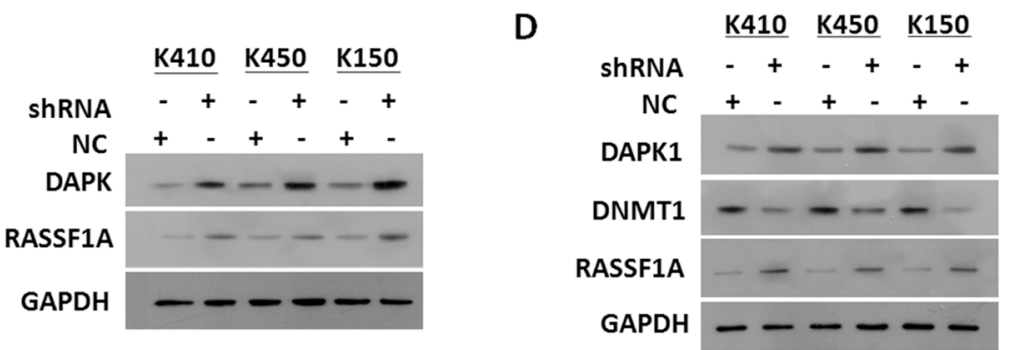

C
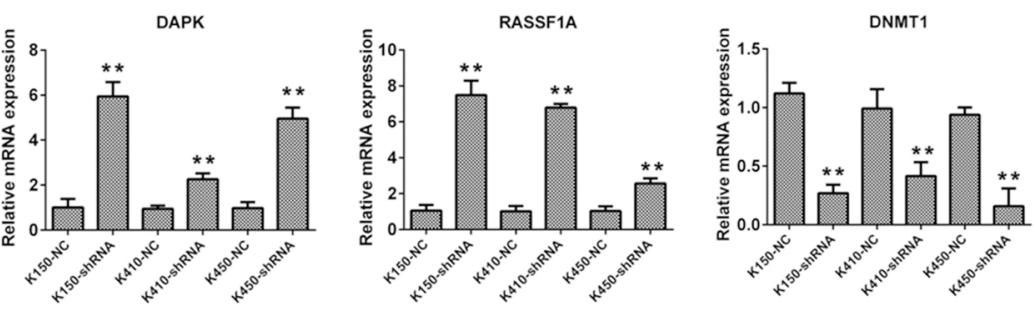

$\mathrm{E}$

DAPK

ShRNA

RASSF1A

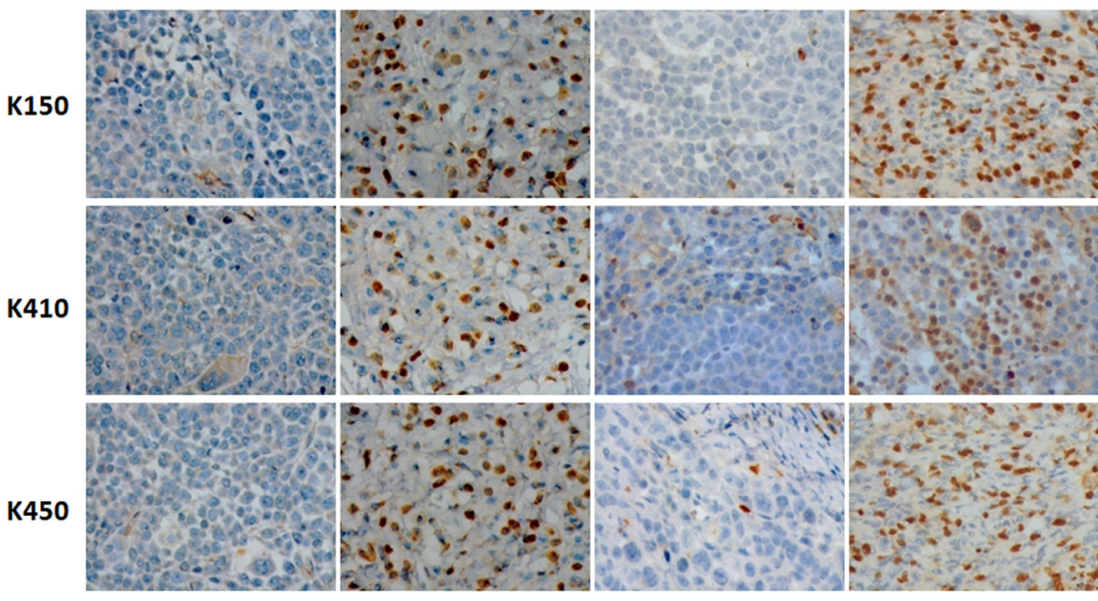

Figure 5: Silencing DNMT1 up-regulated expression of RASSF1A and DAPK. A. The mRNA expression of DAPK, MGMT, RASSF1A, APC, DNMT1, ASC, P16 and CDH13 in ESCC stable cells. mRNA expression of tumor suppressors was normalized to GAPDH. Data represented as means \pm SD. $*, p<0.05 .{ }^{* *}, p<0.01$. B. The protein expression of DAPK and RASSF1A in ESCC cells. GAPDH was served as loading control. C. The mRNA expression of DAPK, RASSF1A and DNMT1 in tumors isolated from nude mice injected with ESCC stable cells. mRNA expression of tumor suppressors was normalized to GAPDH. Data represented as means $\pm \mathrm{SD} . *^{*}, p$ $<0.05$.**, $p<0.01$. D. The protein expression of DAPK and RASSF1A in tumors isolated from nude mice injected with ESCC stable cells. GAPDH was served as loading control. Data represented as means $\pm \mathrm{SD} .{ }^{*}, p<0.05 .{ }^{* *}, p<0.01$. E. IHC staining of DAPK and RASSF1A in tumors isolated from nude mice injected with ESCC stable cells. 
A

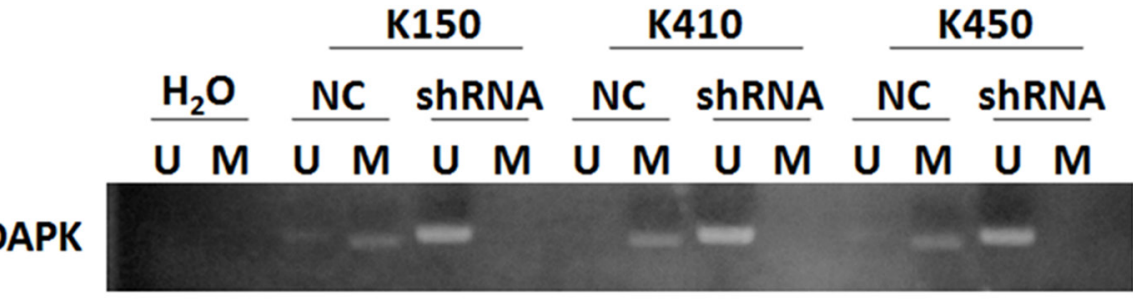

RASSF1A

B

\begin{tabular}{|c|c|c|c|c|c|c|}
\hline \multirow[b]{2}{*}{$\mathrm{H}_{2} \mathrm{O}$} & \multicolumn{2}{|c|}{ K150 } & \multicolumn{2}{|c|}{ K410 } & \multicolumn{2}{|c|}{ K450 } \\
\hline & NC & ShRNA & NC & shRNA & NC & ShRNA \\
\hline$U \mathrm{M}$ & U M & $\mathbf{U} \mathbf{M}$ & $U M$ & U M & $U \mathrm{M}$ & U M \\
\hline & $=$ & - & - & - & - & - \\
\hline
\end{tabular}

RASSF1A

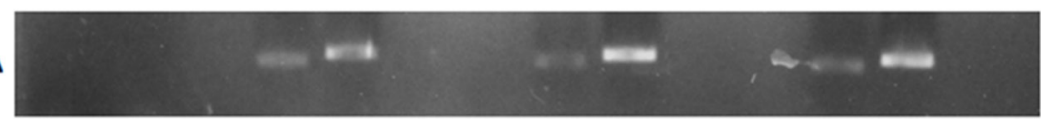

Figure 6: Silencing DNMT1 suppressed methylation in promoter of RASSF1A and DAPK. A. Methylation status of RASSF1A and DAPK in ESCC stable cells. B. Methylation status of RASSF1A and DAPK in tumors isolated from nude mice injected with ESCC stable cells.

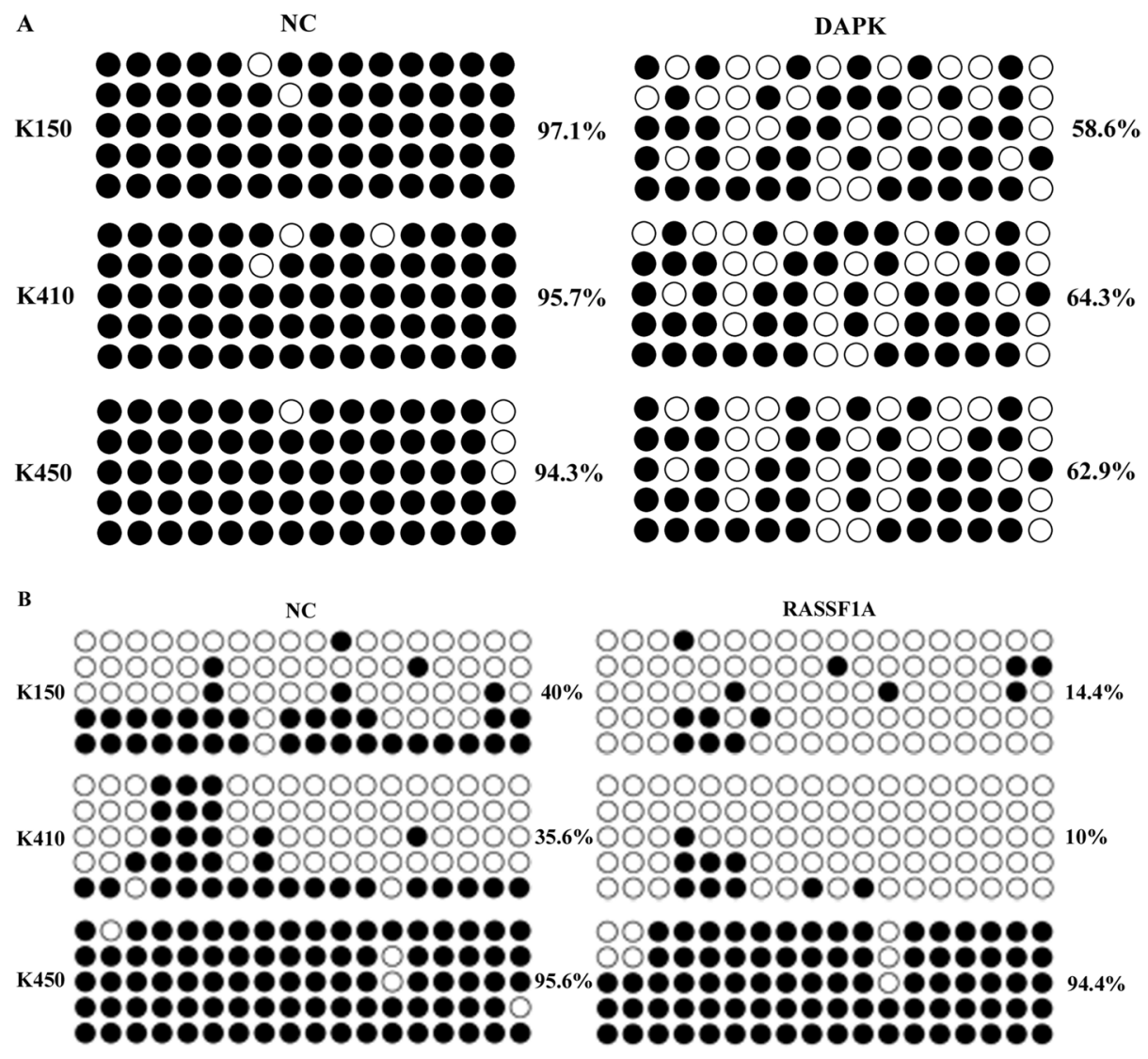

Figure 7: Bisulfite sequencing of the DAPK and RASSF1A CpG island in three ESCC stable cells. Open and filled circles represent unmethylated and methylated $\mathrm{CpG}$ sites, respectively. Each horizontal row represents a single clone. There are 14 and $18 \mathrm{CpG}$ sites in the region of DAPK and RASSF1A, respectively. 
frequently hypermethylated in ESCC. We found DAPK and RASSF1A were up-regulated in ESCC stable cells, in which DNMT1 was suppressed by shRNA. Similar results were also obtained in tumors isolated from nude mice, which were injected with ESCC stable cells. Moreover, methylation status of DAPK and RASSF1A were suppressed in ESCC stable cells and tumors isolated from nude mice. These data indicate that depletion of DNMT1 leads to suppression of methylation in $\mathrm{CpG}$ island and reexpression of DAPK and RASSF1A in ESCC.

In current study, expression of MGMT, APC, ASC and CDH13 in ESCC stable cells weren't increased by silencing DNMT1. One of the possible explanations is that methylation of tumor related genes is changed in different stage of cancers, including ESCC. e.g. methylation of p16 is a frequent and early event in ESCC [33], methylation of CDH13 is associated with high grade and advanced stage cancer $[34,35]$. In vitro assays used in this study only reveal effects of silencing DNMT1 on methylation in one aspect, but cannot mimic the progression of ESCC. In vivo model which can present progression of ESCC hasn't been developed yet.

In conclusion, our data support the hypothesis that silencing DNMT1 inhibits proliferation, metastasis and invasion in ESCC by suppressing methylation of RASSF1A and DAPK. Although this work reveal the potential of DNMT1 as therapeutic target of ESCC, further investigation is needed to unveil the mystery about utilizing DNMT1 to develop tumor-oriented reagent for WSCC therapy.

\section{MATERIALS AND METHODS}

\section{Cell culture}

ESCC cell lines KYSE-150, KYSE-410 and KYSE-450 were obtained from Shanghai Cell Institute, (Shanghai, China). K150, K410 and K450 cells were grown in 1640 medium with $10 \%$ fetal bovine serum (FBS) (GIBCo/BRL, MD), supplemented with 100U/ml penicillin $\mathrm{G}$ and $100 \mu \mathrm{g} / \mathrm{ml}$ streptomycin (Sigma-Aldrich Corp., St. Louis, MO). Cells were maintained at $37^{\circ} \mathrm{C}$ in a humidified 5\% CO2 incubator.

\section{Lentivirus production and transduction}

Lentivirus expressing shRNA targeted DNMT1 were obtained from GenePharma Co., Ltd (China). To generate lentivirus, pWPXL-shRNA or pWPXL vector were transfected together with psPAX2 and pMDG2 into HEK293T cells using lipofectamine 2000 reagent. For transient infection, ESCC cells were infected with the recombinant lentivirus in the presence of $5 \mu \mathrm{g} / \mathrm{mL}$ Polybrene (Sigma). The impacts of of DNMT1-shRNA on ESCC cell lines were measured after transfected for $48 \mathrm{~h}$ (Supplementary Figure S1).

\section{Creation of stable cells}

ESCC cells were infected with recombinant lentivirus in the presence of $5 \mu \mathrm{g} / \mathrm{mL}$ Polybrene (Sigma). Infected cells were selected for 14 days in the presence of $2 \mu \mathrm{g} / \mathrm{mL}$ puromycin. (Sigma). Expression of DNMT1 in infected cells was verified by quantitative reverse transcription PCR (qRT-PCR) and western blot analysis. The expression of DNMT3a and DNMT3b in the stableknockdown cells was detected by quantitative real time RT-PCR and western blot (Supplementary Figure S2).

\section{Quantitative real time RT-PCR (qRT-PCR)}

Total RNA was extracted using TRIZOL reagent (Ambion) according to manufacturers' protocols. cDNA used to examined expression of DNMT1, RASSF1A and DAPK were synthesized by using PrimeScriptTM RT reagent kit (TaKaRa) according to manufacturers' protocols. Expression of DNMT1, RASSF1A and DAPK was examined using SYBR ${ }^{\circledR}$ Premix Ex TaqTM II (TaKaRa) and GAPDH was served as internal reference. All experiments were performed in duplicate and repeated twice. Results are represented as fold induction using the 2- $\Delta \Delta \mathrm{Ct}$ method. Primers used to examined expression of DNMT1, RASSF1A and DAPK were listed in Table 1.

\section{Western blot analysis}

Western blot analysis was performed according to standard Western blot procedures as previously described. Briefly, proteins were separated by $10 \%$ SDS-PAGE and then transferred to nitrocellulose membrane (Bio-Rad). After blocking in 5\% nonfat milk, the membranes were incubated with the following primary antibodies: mouse anti-DNMT1 monoclonal antibody (mAb; 1:300; Abcam), mouse anti-DAPK monoclonal antibody (mAb; 1:300; ABGENT), mouse anti-RASSF1A monoclonal antibody (mAb; 1:300; ABGENT), mouse anti-GAPDH mAb $(1: 1,000 ; A B G E N T)$. The proteins were visualized with enhanced chemiluminescence reagents (Pierce).

\section{Proliferation assays}

Cell Counting Kit-8 (CCK8) was used evaluate cell growth of ESCC cells according to the manufacturer's protocol. Briefly, $1 \times 104$ cells/well were plated in triplicate in 96-well plates. The CCK8 solution was added to each well at a 1:10 dilution. Cells were incubated for $4 \mathrm{~h}$, and the absorbance at $450 \mathrm{~nm}$ was measured using a multi-well plate reader.

\section{Colony formation assays}

Colony formation assays was performed as previously described. Briefly, 100 cells/well were plated in triplicate in 6-well plates and cultured for one week to form colonies. 


\begin{tabular}{|c|c|}
\hline ID & Sequence(5'-3') \\
\hline CDH13 F1 & AGTGTTCCATATCAATCAGCCAG \\
\hline CDH13 R1 & CCTTACAGTCACTGAAGGTCAAG \\
\hline MGMT F1 & ACCGTTTGCGACTTGGTACTT \\
\hline MGMT R1 & GGAGCTTTATTTCGTGCAGACC \\
\hline APC F1 & TCCTGTCCCTGTATCAGAGACT \\
\hline APC R1 & ACTGTGTTTGCTTGAGCTGCT \\
\hline ASC F1 & AGAATTGATGGCCGGAATTACAG \\
\hline ASC R1 & TGGAGCCTTGATAGAAGTCCTC \\
\hline DNMT1 F1 & ССТCTATGGAAGGCTCGAGT \\
\hline DNMT1 R1 & TCACCACACGGTGCTGCTCT \\
\hline GAPDH F & ACACССАСТССТССАССТTТ \\
\hline GAPDH R & TTACTCCTTGGAGGCCATGT \\
\hline DAPK F & TGGATATGACAAAGACACATC \\
\hline DAPK R & CTTCATGTCCTTTGACCCAGA \\
\hline RASSF1A F & ACAGCAACCTCTTCATGAGCT \\
\hline RASSF1A R & CAAGGAGGGTGGCTTCTTGCT \\
\hline p16 F & TGAAAGAACCAGAGAGGCTCT \\
\hline p16 R & TGTAGGACCTTCGGTGACTGAT \\
\hline
\end{tabular}

Colonies were stained with crystal violet staining solution for $20 \mathrm{~min}$, and then the number of colonies was recorded.

\section{Transwell assays}

The assay was done by using chambers with polycarbonate filters (pore size, $8 \mu \mathrm{m}$ ) (Becton Dickinson Labware). ESCC cells were harvested and $5 \times 104$ cells in $200 \mu \mathrm{L}$ of $0.1 \%$ serum medium were placed in the upper chamber. The lower chamber was filled with $10 \%$ fetal bovine serum medium $(600 \mu \mathrm{L})$. After $24 \mathrm{~h}$ incubation and removal of the cells on the upper chamber of the filter with a cotton swab, the cells on the underside were fixed with $4 \%$ paraformaldehyde, stained with $0.1 \%$ crystal violet in $20 \%$ ethanol, and counted in five randomly selected fields under phase contrast microscope. The migrated cells were monitored by photographing at $400 \times$ magnification with LEICA Microscope. The assays were performed in triplicate.

\section{Tumori genesis assays}

Six-week-old female athymic nude mice were subcutaneously injected in the right armpit region with $1 \times 107$ cells in $0.1 \mathrm{~mL}$ of PBS. Two groups of mice(n $=6$ /group) were tested. Group 1 (NC) was injected with ESCC cells infected with NC; and group 2 (shRNA) was injected with ESCC cells infected with lentivirus containing shRNA targeted DNMT1. The tumor sizes was measured every 7 days with calipers. The tumor volume was calculated with the formula: $(\mathrm{L} \times \mathrm{W} 2) / 2$, where $\mathrm{L}$ is the length and $\mathrm{W}$ is the width of the tumor. After the mice were killed at five weeks, the weights of the tumors were measured. All experimental procedures involving animals were in accordance with the Guide for the Care and Use of Laboratory Animals (NIH publication no. 80-23, revised 1996) and were performed according to the institutional ethical guidelines for animal experiments.

\section{Cell cycle analysis}

For cell cycle analysis, $2 \times 105$ cells were plated in a 6-well culture plate and grown for $24 \mathrm{~h}$. Cells were trypsinized, washed twice with cold PBS and fixed with cold $70 \%$ ethanol at $-4^{\circ} \mathrm{C}$ overnight. The cells were then washed twice with PBS and incubated with $10 \mathrm{mg} / \mathrm{ml}$ RNase A, 400 $\mathrm{mg} / \mathrm{ml}$ propidium iodide (Sigma-Aldrich) and $0.1 \%$ Triton-X in PBS at room temperature (RT) for $30 \mathrm{~min}$. Cells were subsequently analyzed by flow cytometry.

\section{Apoptosis assays}

Annexin V-FITC apoptosis detection kit (MUTISCIENCES, China) was used to detect apoptosis in ESCC cells. According to manufacturer's instruction manual, the cells were digested with trypsin, and centrifuged on $2000 \mathrm{rpm}$ for $5 \mathrm{~min}$. After collection, the cells 


\begin{tabular}{lc}
\hline ID & Sequence(5'- $\left.\mathbf{3}^{\prime}\right)$ \\
\hline DNMT1-U-F & TTAGTAAATTGTGGAGTTTGGATGA \\
DNMT1-U-R & TACAAAAAAATAAAACAAAACCAAC \\
DNMT1-M-F & TTTTAGTAAATCGTGGAGTTTGGAC \\
DAPK-M-R & TACAAAAAAATAAAACGAAACCGAC \\
DAPK-U-F & GGAGGATAGTTGGATTGAGTTAATGTT \\
DAPK-U-R & CAAATCCCTCCCAAACACCAA \\
DAPK-M-F & GGATAGTCGGATCGAGTTAACGTC \\
DAPK-M-R & CCCTCCCAAACGCCGA \\
RASSF1A-U-F & GGGGTTTGTTTTGTGGTTTTGTTT \\
RASSF1A-U-R & AACATAACCCAATTAAACCCATACTTCA \\
RASSF1A-M-F & GGGTTCGTTTTGTGGTTTCGTTC \\
RASSF1A-M-R & TAACCCGATTAAACCCGTACTTCG \\
\hline
\end{tabular}

were washed twice with PBS, and centrifuged on 2000rpm for $5 \mathrm{~min}, 1-5 \times 105$ cells were collected and suspensed with $500 \mu \mathrm{l}$ Binding Buffer. $5 \mu \mathrm{l}$ Annexin V-FITC and $5 \mu \mathrm{l}$ Propidium Iodide was respectively added and mixed on room temperature, and away from light for $15 \mathrm{~min}$. Within 1 hour, the cells were detected by flow cytometry.

\section{Immunohistochemistry staining}

The tumors was isolated, post-fixed in cold $4 \%$ paraformaldehyde overnight, and embedded in paraffin. Transverse paraffin sections ( $5 \mu \mathrm{m}$ thickness) were mounted in Poly-L-Lysine-coated slides for histopathological examination. The tumor sections stained with hematoxylin and eosin for HE staining following the instruction. Consecutive slides were immunostained. The slide were incubated in $3 \% \mathrm{H} 2 \mathrm{O} 2$ for $15 \mathrm{~min}$ and $80 \%$ carbinol for $30 \mathrm{~min}$ and then in blocking solution for $1 \mathrm{~h}$ at room temperature. Subsequently, the sections were incubated at $4^{\circ} \mathrm{C}$ overnight with the following primary antibodies: DAPK (1:150) and RASSF1A (1:200). After triple washing in PBS, the sections were incubated with horseradish peroxidaseconjugated secondary antibodies for $2 \mathrm{~h}$ at $37^{\circ} \mathrm{C}$. The reaction was stopped with 3, 3-diaminobenzidine (DAB). The results were imaged at a magnification of 400 using a Nikon ECLPSE 80i (Nikon, Japan). The optical densities and positive cell numbers of DAPK and RASSF1A were counted at 5 randomly selected fields per sample in spinal anterior horn and quantification by Imagepro-Plus. Histology and immunohistochemistry for each marker were performed simultaneously in all samples as well as negative controls without primary antibodies.

\section{Methylation-specific polymerase chain reaction (MSP)}

MSP was performed as previously described [6]. Genomic DNA $(1 \mu \mathrm{g})$ was harvested with a DNA rapid extraction kit for bisulfite modification with the $\mathrm{CpG}$ genome kit according to the manufacturer's instructions; $5 \mu \mathrm{L}$ of bisulfite-modified DNA was used per $25 \mu \mathrm{L}$ methylation-specific PCR (MSP) reaction. For PCR, methylated (M) and unmethylated (U) primer pairs were initially denatured at $94^{\circ} \mathrm{C}$ for 3 min followed by 35 cycles with a 1 -min denaturation step, $30 \mathrm{~s}$ of annealing at $60^{\circ} \mathrm{C}\left(\right.$ demethylation $\left.58^{\circ} \mathrm{C}\right)$, and $3 \mathrm{~min}$ of extension at $72^{\circ} \mathrm{C}$. Final extension after 35 cycles was at $72^{\circ} \mathrm{C}$ for $10 \mathrm{~min}$, and the product was stored at $4^{\circ} \mathrm{C}$. PCR products were analyzed by agarose gel electrophoresis and ethidium bromide staining, and the objective gene stripes were used as the positive expression. The methylation-specific primers and the unmethylation-specific primers used in MSP were listed in Table 2.

\section{Bisulphite sequences assay (BSP)}

Bisulphite sequences assay was performed to demonstrate the methylation status of RASSF1A and DAPK promoters in three ESCC stable cell lines (K150shRNA, K410-shRNA and K450-shRNA). Genomic DNA from cell lines was isolated with Easypure Genomic DNA kit (TransGen Biotech, Beijing, China). Genomic DNA was subjected to bisulfite conversion and purification using the EZ DNA MethylationGoldTM Kit (Zymo Research Corporation, CA, USA) according to the manufacturer's instructions. The BSP primer (Supplementary Table S1) was designed by Methprimer or Methyl Primer Express v1.0. Amplified PCR Products were purified and cloned into pMD19-T (TaKaRa, Dalian, China), 5 clones each cell were sequenced. Percentage of methylation was calculated comprehensively and comparatively by $\mathrm{CpG}$ viewer, QUMA and Biq-analyzer. The primer sequence for BSP were listed in table 3. 
Table 3: The primer sequence for BSP in this reasearch

\begin{tabular}{lc}
\hline primer & \multicolumn{1}{c}{$\mathbf{5}-\mathbf{3}}$, \\
\hline DAPK-BSP-F & GAGGTTTTTAGTGGATATGGGATTT \\
DAPK-BSP-R & TCCACCTCCAAAATTCAAATAATT \\
RASSF1A-BSP-F & TTATTTAGTGGGTAGGTTAAGTGTGTT \\
RASSF1A-BSP-R & CCTAAATACAAAAACTATAAAACCC \\
\hline
\end{tabular}

\section{Statistical analysis}

Data were shown as mean \pm SD unless otherwise noted; the Student's t test was used to analyze statistical difference between group NC and group shRNA. P value of $<0.05$ was considered statistically significant.

\section{ACKNOWLEDGMENTS}

We thank the members of our laboratories for their insight and technical support.

\section{CONFLICTS OF INTEREST}

The authors declare no conflicts of interest.

\section{FINANCIAL SUPPORT}

This work was supported by National Natural Science Foundation of China, Grant Number: No.81160273, 81160296 .

\section{REFERENCES}

1. Vos MD, Clark GJ. RASSF family proteins and Ras transformation. Methods Enzymol. 2006; 407:311-322.

2. Chan MW, Chan LW, Tang NL, Lo KW, Tong JH, Chan AW, Cheung HY, Wong WS, Chan PS, Lai FM, To KF. Frequent hypermethylation of promoter region of RASSF1A in tumor tissues and voided urine of urinary bladder cancer patients. Int J Cancer. 2003; 104:611-616.

3. Wagner KJ, Cooper WN, Grundy RG, Caldwell G, Jones C, Wadey RB, Morton D, Schofield PN, Reik W, Latif F, Maher ER. Frequent RASSF1A tumour suppressor gene promoter methylation in Wilms' tumour and colorectal cancer. Oncogene. 2002; 21:7277-7282.

4. van Engeland M, Roemen GM, Brink M, Pachen MM, Weijenberg MP, de Bruine AP, Arends JW, van den Brandt PA, de Goeij AF, Herman JG. K-ras mutations and RASSF1A promoter methylation in colorectal cancer. Oncogene. 2002; 21:3792-3795.

5. Liu L, Yoon JH, Dammann R, Pfeifer GP. Frequent hypermethylation of the RASSF1A gene in prostate cancer. Oncogene. 2002; 21:6835-6840.
6. Du Z, Ma K, Sun X, Li A, Wang H, Zhang L, Lin F, Feng $\mathrm{X}$, Song J. Methylation of RASSF1A gene promoter and the correlation with DNMT1 expression that may contribute to esophageal squamous cell carcinoma. World J Surg Oncol. 2015; 13:141.

7. Feinstein E, Druck T, Kastury K, Berissi H, Goodart SA, Overhauser J, Kimchi A, Huebner K. Assignment of DAP1 and DAPK--genes that positively mediate programmed cell death triggered by IFN-gamma--to chromosome regions 5p12.2 and 9q34.1, respectively. Genomics. 1995; 29:305-307.

8. Gozuacik D, Kimchi A. DAPk protein family and cancer. Autophagy. 2006; 2:74-79.

9. Mittag F, Kuester D, Vieth M, Peters B, Stolte B, Roessner A, Schneider-Stock R. DAPK promotor methylation is an early event in colorectal carcinogenesis. Cancer Lett. 2006; 240:69-75.

10. Robert MF, Morin S, Beaulieu N, Gauthier F, Chute IC, Barsalou A, MacLeod AR. DNMT1 is required to maintain CpG methylation and aberrant gene silencing in human cancer cells. Nat Genet. 2003; 33:61-65.

11. Rhee I, Bachman KE, Park BH, Jair KW, Yen RW, Schuebel KE, Cui H, Feinberg AP, Lengauer C, Kinzler KW, Baylin SB, Vogelstein B. DNMT1 and DNMT3b cooperate to silence genes in human cancer cells. Nature. 2002; 416:552-556.

12. Bashtrykov P, Jeltsch A. DNMT1-associated DNA methylation changes in cancer. Cell Cycle. 2015; 14:5.

13. Raggi C, Factor VM, Seo D, Holczbauer A, Gillen MC, Marquardt JU, Andersen JB, Durkin M, Thorgeirsson SS. Epigenetic reprogramming modulates malignant properties of human liver cancer. Hepatology. 2014; 59:2251-2262.

14. Xiang J, Luo F, Chen Y, Zhu F, Wang J. si-DNMT1 restore tumor suppressor genes expression through the reversal of DNA hypermethylation in cholangiocarcinoma. Clin Res Hepatol Gastroenterol. 2014; 38:181-189.

15. Garzon R, Liu S, Fabbri M, Liu Z, Heaphy CE, Callegari E, Schwind S, Pang J, Yu J, Muthusamy N, Havelange V, Volinia S, Blum W, Rush LJ, Perrotti D, Andreeff M, et al. MicroRNA-29b induces global DNA hypomethylation and tumor suppressor gene reexpression in acute myeloid leukemia by targeting directly DNMT3A and 3B and indirectly DNMT1. Blood. 2009; 113:6411-6418. 
16. Wang YS, Chou WW, Chen KC, Cheng HY, Lin RT, Juo SH. MicroRNA-152 mediates DNMT1-regulated DNA methylation in the estrogen receptor alpha gene. PLoS One. 2012; 7:e30635.

17. Takata A, Otsuka M, Yoshikawa T, Kishikawa T, Hikiba Y, Obi S, Goto T, Kang YJ, Maeda S, Yoshida H, Omata M, Asahara H, Koike K. MicroRNA-140 acts as a liver tumor suppressor by controlling NF-kappaB activity by directly targeting DNA methyltransferase 1 (Dnmt1) expression. Hepatology. 2013; 57:162-170.

18. Aguirre-Arteta AM, Grunewald I, Cardoso MC, Leonhardt $\mathrm{H}$. Expression of an alternative Dnmt1 isoform during muscle differentiation. Cell Growth Differ. 2000; 11:551-559.

19. Rai K, Nadauld LD, Chidester S, Manos EJ, James SR, Karpf AR, Cairns BR, Jones DA. Zebra fish Dnmt1 and Suv39h1 regulate organ-specific terminal differentiation during development. Mol Cell Biol. 2006; 26:7077-7085.

20. Lee PP, Fitzpatrick DR, Beard C, Jessup HK, Lehar S, Makar KW, Perez-Melgosa M, Sweetser MT, Schlissel MS, Nguyen S, Cherry SR, Tsai JH, Tucker SM, Weaver WM, Kelso A, Jaenisch R, et al. A critical role for Dnmt1 and DNA methylation in T cell development, function, and survival. Immunity. 2001; 15:763-774.

21. Tsai CC, Su PF, Huang YF, Yew TL, Hung SC. Oct4 and Nanog directly regulate Dnmtl to maintain self-renewal and undifferentiated state in mesenchymal stem cells. Mol Cell. 2012; 47:169-182.

22. Tsumura A, Hayakawa T, Kumaki Y, Takebayashi S, Sakaue M, Matsuoka C, Shimotohno K, Ishikawa F, Li E, Ueda HR, Nakayama J, Okano M. Maintenance of self-renewal ability of mouse embryonic stem cells in the absence of DNA methyltransferases Dnmt1, Dnmt3a and Dnmt3b. Genes Cells. 2006; 11:805-814.

23. Kim M, Trinh BN, Long TI, Oghamian S, Laird PW. Dnmt1 deficiency leads to enhanced microsatellite instability in mouse embryonic stem cells. Nucleic Acids Res. 2004; 32:5742-5749.

24. Liu CC, Ou TT, Wu CC, Li RN, Lin YC, Lin CH, Tsai WC, Liu HW, Yen JH. Global DNA methylation, DNMT1, and MBD2 in patients with systemic lupus erythematosus. Lupus. 2011; 20:131-136.

25. Peters SL, Hlady RA, Opavska J, Klinkebiel D, Novakova S, Smith LM, Lewis RE, Karpf AR, Simpson MA, Wu L, Opavsky R. Essential role for Dnmt1 in the prevention and maintenance of MYC-induced T-cell lymphomas. Mol Cell Biol. 2013; 33:4321-4333.

26. Valdez CD, Kunju L, Daignault S, Wojno KJ, Day ML. The E2F1/DNMT1 axis is associated with the development of AR negative castration resistant prostate cancer. Prostate. 2013; 73:1776-1785.

27. Cheray M, Pacaud R, Nadaradjane A, Vallette FM, Cartron PF. Specific inhibition of one DNMT1-including complex influences tumor initiation and progression. Clin Epigenetics. 2013; 5:9.

28. Shen N, Yan F, Pang J, Wu LC, Al-Kali A, Litzow MR, Liu $\mathrm{S}$. A nucleolin-DNMT1 regulatory axis in acute myeloid leukemogenesis. Oncotarget. 2014; 5:5494-5509. doi: 10.18632/oncotarget.2131.

29. Pathania R, Ramachandran S, Elangovan S, Padia R, Yang P, Cinghu S, Veeranan-Karmegam R, Arjunan P, GnanaPrakasam JP, Sadanand F, Pei L, Chang CS, Choi JH, Shi H, Manicassamy S, Prasad PD, et al. DNMT1 is essential for mammary and cancer stem cell maintenance and tumorigenesis. Nat Commun. 2015; 6:6910.

30. Kinney SR, Moser MT, Pascual M, Greally JM, Foster BA, Karpf AR. Opposing roles of Dnmt1 in early- and late-stage murine prostate cancer. Mol Cell Biol. 2010; 30:4159-4174.

31. Tennis MA, Vanscoyk MM, Wilson LA, Kelley N, Winn RA. Methylation of Wnt7a is modulated by DNMT1 and cigarette smoke condensate in non-small cell lung cancer. PLoS One. 2012; 7:e32921.

32. Leu YW, Rahmatpanah F, Shi H, Wei SH, Liu JC, Yan PS, Huang TH. Double RNA interference of DNMT3b and DNMT1 enhances DNA demethylation and gene reactivation. Cancer Res. 2003; 63:6110-6115.

33. Guo M, Ren J, House MG, Qi Y, Brock MV, Herman JG. Accumulation of promoter methylation suggests epigenetic progression in squamous cell carcinoma of the esophagus. Clin Cancer Res. 2006; 12:4515-4522.

34. Lin YL, Xie PG, Ma JG. Aberrant methylation of CDH13 is a potential biomarker for predicting the recurrence and progression of non muscle invasive bladder cancer. Med Sci Monit. 2014; 20:1572-1577.

35. Wang Z, Yuan X, Jiao N, Zhu H, Zhang Y, Tong J. CDH13 and FLBN3 gene methylation are associated with poor prognosis in colorectal cancer. Pathol Oncol Res. 2012; $18: 263-270$. 